\title{
Muscle Oxygenation and Time to Task Failure of Submaximal Holding and Pulling Isometric Muscle Actions and Influence of Intermittent Voluntary Muscle Twitches
}

\section{Silas Dech ( $\sim$ dech@uni-potsdam.de)} University of Potsdam

Frank N. Bittmann

University of Potsdam

Laura V. Schaefer

University of Potsdam

\section{Research Article}

Keywords: oxygen saturation, microvascular blood filling, isometric contraction, isometric muscle action, holding isometric muscle action, pulling isometric muscle action, pushing isometric muscle action, time to task failure, muscle twitch

Posted Date: February 10th, 2022

DOI: https://doi.org/10.21203/rs.3.rs-1307566/v1

License: (c) (1) This work is licensed under a Creative Commons Attribution 4.0 International License.

Read Full License 


\section{Abstract}

Background: Isometric muscle actions (IMA) can be performed either by initiating the action, e.g., pulling on an immovable resistance (PIMA), or by reacting to an external load, e.g., holding a weight (HIMA). In the present study, it was mainly examined if these forms could be differentiated by oxidative variables as well as by time to task failure (TTF). Furthermore, it was analyzed if variables are changed by intermittent voluntary muscle twitches during weight holding (Twitch). It was assumed that twitches during a weight holding task turn the character from reacting (스 HIMA) to acting (스 PIMA).

Methods: Twelve subjects (two drop outs) performed HIMA and randomly PIMA or Twitch with the elbow flexors at $60 \%$ of maximal torque maintained until muscle failure with each arm. Capillary venous oxygen saturation (SvO2) and relative hemoglobin amount $(\mathrm{rHb})$ were measured by white light spectrometry.

Results: Within subjects, no significant differences were found between tasks regarding the behavior of $\mathrm{SvO} 2 \mathrm{and} \mathrm{rHb}$, the slope and extent of deoxygenation, SvO2 level at global rHb minimum, and time to SvO2 steady states. The TTF was significantly longer during Twitch and PIMA (incl. Twitch) compared to HIMA ( $p=0.043$ and 0.047 , respectively). There was no substantial correlation between TTF and maximal deoxygenation independently of the task $(r=-0.13)$.

Conclusions: HIMA and PIMA seem to have a similar microvascular oxygen and blood supply. The supply might be sufficient, which is expressed by homeostatic steady states of SvO2 in all and increases in $\mathrm{rHb}$ in most of the trials. Intermittent muscle twitches might not serve as a further support but extend the TTF. A changed neuromuscular control is discussed as possible explanation.

\section{Background}

Isometric muscle actions (IMA) can be performed during two different tasks. On the one hand, a person can apply force by pushing against or pulling on a stable resistance (e.g., common determination of the maximal voluntary isometric contraction (MVIC)). The person acts with the attempt to shorten the muscle but this is prevented by the stable resistance, hence the muscle action stays isometrically [1]. This refers to a pushing or pulling isometric muscle action (PIMA) [2]. It has also been called "force task" [35] "restrained task" [6], or "concentrically loaded isometric contraction"[1]. On the other hand, a person can react to an external load by holding a position. The person reacts with the attempt to resist the externally provoked lengthening [1] by adapting to the applied load. The external load can be, e.g., a constant weight or increasing force for assessment of the maximal isometric Adaptive Force [7, 8]. Such muscle action refers to a "holding isometric muscle action" (HIMA) [2]. It was also termed "position task" [3-5], "postural task" [6], or "eccentrically loaded isometric contraction" [1].

In previous studies, both isometric tasks could partly be differentiated by various variables $[2-5,7,9-$ 11]. Most consistently, the time to task failure (TTF) was found to be significantly shorter during HIMA compared to PIMA at low intensities (15\%,20\% and $30 \%$ of the MVIC) performed by arm flexor muscles in a horizontal forearm position $[3,4,9,11]$. With a vertically positioned forearm and at intensities of $45 \%$, 
$60 \%$ and $80 \%$ conflicting results has been found $[2-4,10]$. Other variables which had shown differences between isometric tasks were amplitudes of electromyography (EMG) or mechanomyography (MMG) at exhaustion (PIMA > HIMA) [2,3], normalized EMG power (spectral analysis) in a frequency band of 10 $29 \mathrm{~Hz}$ (PIMA > HIMA) [4], MTG power frequency ranges of $8-15 \mathrm{~Hz}$ as well as $10-29 \mathrm{~Hz}$ (HIMA > PIMA) [2], mean arterial blood pressure (HIMA > PIMA) [3], glucose uptake in young men (HIMA > PIMA) [5] and the maximal torque [7].

However, there are also studies which did not reveal a difference between HIMA and PIMA in none of their analyzed parameters: MVIC, TTF and mean heart rate relative to rest for biceps brachii muscle [12]; motor unit discharge characteristics and the extent of motor unit synchronization at $4.4 \%$ of the MVIC (PIMA) or $3.8 \%$ of the one-repetition maximum (HIMA) for first dorsal interosseus muscle [6] as well as EMG amplitudes at $20 \%, 30 \%, 40 \%$, and $50 \%$ of the MVIC for soleus muscle [1].

Regarding muscle oxygenation, Booghs et al. (2012) analyzed tissue oxygenation index (TOI) and normalized total hemoglobin index (nTHI) of the biceps brachii muscle between HIMA and PIMA at 20\% and $60 \%$ of the MVIC [11]. They found similar behaviors for both tasks at both intensities. However, at $60 \%$, the TOI seemed to decrease more during PIMA compared to HIMA. A statistical comparison was not provided.

The main objective of the present study was to compare the capillary venous oxygen saturation $\left(\mathrm{SvO}_{2}\right)$ and relative hemoglobin amount $(\mathrm{rHb})$ between HIMA and PIMA maintained until muscle failure (fatiguing task). Previous studies have revealed that during IMA homeostatic steady states in the oxygen saturation are possible even at submaximal and maximal intensities [11, 13-17]. Thus, not only the extent and slopes of deoxygenation but also time to leveling off into a steady state were compared between HIMA and PIMA in the present study. Our research group differentiated two behavioral types in the regulation of oxygen saturation $\left(\mathrm{SvO}_{2}\right)$ and blood filling $(\mathrm{rHb})$ [13]. In type I, $\mathrm{SvO}_{2}$ and $\mathrm{rHb}$ generally decrease and level off into steady states. Both parameters behave nearly parallel to each other. In contrast, an increase in $\mathrm{rHb}$ despite a further decrease in $\mathrm{SvO}_{2}$ is the main characteristic of type II. Thus, the behavior is partly inverse. The occurrence of type I or type II was also documented in the present study. Our research group suggested the type depends on the oxygenation level [17]. The increase in $\mathrm{rHb}$ after reaching its global minimum (type II) might be triggered if $\mathrm{SvO}_{2}$ level drops below 59\% [17]. Thus, the oxygenation level at the moment of global rHb minimum was compared between HIMA and PIMA here.

Furthermore, TTFs were compared between HIMA and PIMA since it seems to be one of the most promising variables as mentioned above. The analyses should gain further data concerning the supposed distinction of two different isometric muscle actions $[1-6,12]$.

It must be noted that a holding task per se does not automatically prevent a muscle shortening (e.g., overcome an applied weight). If tolerated, minimal concentric contractions are possible to compensate for a prior lengthening. At macro level this still might be interpreted as IMA. For that, intermittent rapid 
and short muscle twitches (Twitch) were performed by a subgroup during a weight holding task in the present study. Caused by that kind of minor concentric contractions, the character of IMA might be changed also during the isometric phases [2]: from reacting (HIMA) to acting (PIMA). It was also questioned, if weight holding with additional muscle twitches has an influence on all above-mentioned variables. From a general understanding, IMAs performed at submaximal intensities were supposed to lead to a restriction of oxygen and blood supply caused by high intramuscular pressures [18-22]. Rapid but short auxotonic contractions with minimal motion of the limb (Twitch) might support the capillary blood flow by serving as a kind of pump. Consequently, this might lead to an altered blood and oxygen supply. The TTF might also be changed because of an altered neuromuscular control.

\section{Materials And Methods}

\section{Subjects}

Both biceps brachii muscles of twelve subjects were examined. Two of these had to be excluded due to pain or discomfort during the trials $(n=10 ; 8$ males, 2 females, mean age \pm standard deviation (SD) $=$ $30.70 \pm 11.67$ years, $72.70 \pm 11.00 \mathrm{~kg}, 1.78 \pm 0.08 \mathrm{~m}, \mathrm{BMl}: 22.84 \pm 2.00^{\frac{\mathrm{kg}}{\mathrm{m}^{2}}}$ two lefties).

\section{Measuring technique}

The valid and reliable $02 \mathrm{C}$ spectrophotometer (Oxygen To See; LEA@ Medizintechnik GmbH, Gießen, Germany) recorded $\mathrm{SvO}_{2}$ and $\mathrm{rHb}$ [23-27]. Laser Doppler technique and tissue spectrometry (laser light: near infrared, continuous wave, power $>30 \mathrm{~mW}$; white light: $500-850 \mathrm{~nm}, 1 \mathrm{~nm}$ resolution) are combined in the device $[28,29]$. The device sends white light into the superficial muscle tissue through the measuring probe (LF3, separation: $16 \mathrm{~mm}$, tissue penetration: $12 \mathrm{~mm}$ ). The probe was fixed over the biceps brachii muscle belly along its fibers. The amount of the backscattered light and changed wavelength is used for calculating $\mathrm{rHb}$ in arbitrary units (AU) in dependence of the absorption rate and $\mathrm{SvO}_{2}$ (in \%) as a ratio of oxygenated and deoxygenated hemoglobin. The sampling rate was $40 \mathrm{~Hz}$. To minimize light effects on the probe, the room light was dimmed.

\section{Study design and overall procedure}

All subjects started with a MVIC-test with one arm randomly selected (coin toss). Two different determination methods of the MVIC were utilized according to the following fatiguing task (HP-group performed HIMA and PIMA; HT-group performed HIMA and Twitch (specific description see below). The authors find this acceptable since comparisons were only made within subjects. The sequence of fatiguing tasks was randomized by coin toss. The rest between fatiguing tasks was at least 3 minutes. Afterwards, the same procedure was applied to the other arm. An intensity of $60 \%$ of the MVIC was chosen for the fatiguing tasks according to Booghs et al. (2012) [11], and because it might lead to high intramuscular pressures to restrict the blood and oxygen supply [18]. The recording of parameters $\left(\mathrm{SvO}_{2}\right.$ and $\mathrm{rHb}$ ) started $10 \mathrm{~s}$ before and lasted until two minutes after every task. 
During the MVIC-tests, the subjects of the HP-group sat on a measuring chair in an upright position. They pulled two times as strong as possible on a cuff which was connected to a fixed strain gauge (Figure 1a). Rest between trials was at least two minutes. The cuff was applied $2-3 \mathrm{~cm}$ proximal to the wrist crease of the subject whose upper arm was in contact with the thorax (anteversion - retroversion $0^{\circ}$, adduction - abduction $\left.0^{\circ}\right)$, the elbow joint was flexed $\left(90^{\circ}\right)$ and the forearm was maximally supinated. The highest measured force value of the two trials was determined as MVIC.

During fatiguing PIMA (Figure 1a), the arm and sitting positions were identical to the MVIC-tests. The subjects had to pull on a fixed strain gauge and had to maintain the target force of $60 \%$ of the MVIC for as long as possible. For that, they had visual feedback (pointer) on a monitor. As soon as the force remained below the target for $2 \mathrm{~s}$, the rater prompted the subject to stop the task.

During fatiguing HIMA, the subjects had to hold the respective weight for as long as possible with the same arm position but while standing which allows the weight to hang free (Figure 1b). The weight was taken off as soon as the elbow angle exceeded $90^{\circ}$ for $2 \mathrm{~s}$, assessed by the rater subjectively.

\section{Procedures of the HT-group trials}

The MVIC-test of the HT-group was performed by holding a weight while standing in the same arm and cuff position as described in the HP-group section (Figure 1b). The weights were added progressively within maximal five steps (accuracy: $\pm 1 \mathrm{~kg}$ ), started with an estimated appropriate first weight. For that, the rater hooked the respective weight onto the cuff. The rest between steps had to be sufficient for the subject (30s - 2 min., depending on the load). The highest weight which could be held for $1 \mathrm{~s}$ was determined as MVIC. This procedure does not achieve the same accuracy as determined by strain gauge but was chosen in favor of the fatiguing tasks.

The fatiguing HIMA was performed identically as described for the HP-group. The same applies for the fatiguing Twitch task except for additional intermittent contractions (muscle twitches) every $7 \mathrm{~s}$. For that, an acoustic signal was given. The subjects were instructed to perform twitches rapidly but with a minimal excursion of the forearm. The rater took off the weight as soon as the subject could not twitch again or if the elbow angle exceeded $90^{\circ}$ for $2 \mathrm{~s}$, visually assessed by the rater.

\section{Data processing}

All $\mathrm{SvO}_{2}$ and $\mathrm{rHb}$ curves were smoothed by using the software in NI DIAdem ${ }^{\mathrm{TM}} 2017$ (moving average, maximal smoothing width: 50 ). The following variables were extracted for each trial:

(1.) $\mathrm{SvO}_{2}$ baseline value in $\%$ was quantified by the arithmetic mean (M) of the initial 400 data points $\bumpeq$ first $10 \mathrm{~s}$. 
(2.) maximal deoxygenation (max. $\mathrm{SvO}_{2}$ decrease) was determined as the difference of (1.) to the minimum of $\mathrm{SvO}_{2}$. Values are presented in percent points (pp) and additionally in \% related to the respective baseline value.

(3.) slope of initial linear $\mathrm{SvO}_{2}$ decrease $\left(\mathrm{SvO}_{2}\right.$ slope) was quantified by the slope of the least square regression line. According to Felici et al (2009) [30], intervals for this analysis were set by the borders of the first negative long plateau in the first derivative of the smoothed $\mathrm{SvO}_{2}$ curve.

(4.) $\mathrm{SvO}_{2}$ level at global minimum of $\mathrm{rHb}\left(\mathrm{SvO}_{2}\right.$ at $\mathrm{rHb}$ min.) corresponds to $\mathrm{SvO}_{2}$ value at the reversal point (RP) (type II).

(5.) time to leveling off into a steady state of $\mathrm{SvO}_{2}$ (TSS) is the time period in s from start of loading to the end of the linear phase (start of leveling off into a steady state).

(6.) time to task failure (TTF) was defined as the time period in s from start to end of loading.

According to Dech et al. (2020) [13], the curves were also assigned visually to type I (parallel behavior of $\mathrm{SvO}_{2}$ and $\mathrm{rHb}$, Figure 2a) or type II (increase in $\mathrm{rHb}$ after the RP, Figure 2b). The assignment and all mentioned variables (1. - 6.) of each trial can be found in supplementary material (Table S1).

\section{Statistical analysis}

IBM SPSS Statistics 26 was used for statistical analyses. All trials of two and one arm of two others had to be excluded from statistical analysis due to irritations by the cuff at the place of application. Another trial (Twitch) was excluded because the twitches were not performed accurately. In total, 36 trials of ten subjects were included for statistical analyses (HP and HT $n=9$ trials for each task).

Differences of all mentioned variables (1. - 6.) were compared between fatiguing tasks within subjects (HIMA vs. PIMA (incl. Twitch) and separated by group (HP: HIMA vs. PIMA and HT: HIMA vs. Twitch). Both arms were considered together in all analyses, because MVICs of right $(70.02 \pm 23.83 \mathrm{Nm})$ and left $\operatorname{arm}(69.31 \pm 21.69 \mathrm{Nm})$ did not differ significantly $(t(11)=0.80, p=0.442)$.

All data were normally distributed (Shapiro-Wilk-test, $p>0.05)$, except for baseline values of Twitch $(p=$ $0.017)$ and max. $\mathrm{SvO}_{2}$ decrease of all HIMAs $(p=0.019)$. Regarding normal distributed variables, analyses of differences were made by parametric tests (t-tests for dependent samples). Comparisons including not normally distributed variables were made by exact Wilcoxon signed-rank test. Numbers of type I and type II behaviors per task were compared by Chi-squared test. An alpha error of $5 \%$ was chosen for all tests.

Pearson's correlation coefficients ( $r$ ) were calculated between TTF (6.), max. $\mathrm{SvO}_{2}$ decrease (2.) and $\mathrm{SvO}_{2}$ slope (3.) of all 36 trials. 


\section{Results}

Comparisons of isometric tasks

Tasks did not differ significantly regarding oxidative variables (1. - 5.). In regard of TTF (6.), HIMA and PIMA did not differ significantly despite a trend in favor of PIMA. The TTF during Twitch was about $10 \mathrm{~s}$ longer than during HIMA. This difference was significant $(t(8)=-2.40, p=0.043)$. The comparison of all HIMAs and PIMAs (incl. Twitches) also showed a significant difference $(t(17)=-2.15, p=0.047)$. The inference statistics of all described variables can be found in Table 1.

Table 1. Inference statistics of comparisons between tasks. 


\begin{tabular}{|c|c|c|c|c|c|}
\hline variable & group & $\begin{array}{l}\text { fatiguing } \\
\text { task }\end{array}$ & mean $\pm S D$ & $\begin{array}{l}\text { t-values (df) } \\
\text { / z values }\end{array}$ & $\begin{array}{l}\text { significance } \\
\text { level }\end{array}$ \\
\hline \multirow{6}{*}{$\begin{array}{l}(1 .) \\
\text { baseline value } \\
\text { in } \%\end{array}$} & \multirow[t]{2}{*}{$\mathrm{HP}$} & HIMA & $73.78 \pm 6.63$ & \multirow[t]{2}{*}{$t(8)=-1.53$} & \multirow[t]{2}{*}{$p=0.164$} \\
\hline & & PIMA & $77.44 \pm 4.06$ & & \\
\hline & \multirow[t]{2}{*}{ HT } & HIMA & $74.61 \pm 6.98$ & \multirow[t]{2}{*}{$z=-0.30, n=9$} & \multirow[t]{2}{*}{$p_{\text {exact }}=0.820$} \\
\hline & & Twitch & $74.00 \pm 5.01$ & & \\
\hline & \multirow[t]{2}{*}{ both } & HIMA & $74.19 \pm 6.62$ & \multirow{2}{*}{$\begin{array}{l}z=-1.15, n= \\
18\end{array}$} & \multirow[t]{2}{*}{$p_{\text {exact }}=0.265$} \\
\hline & & $\begin{array}{l}\text { PIMA \& } \\
\text { Twitch }\end{array}$ & $75.72 \pm 4.77$ & & \\
\hline \multirow{12}{*}{$\begin{array}{l}\text { (2.) } \\
\text { max. } \mathrm{SvO}_{2} \\
\text { decrease } \\
\text { in pp (\%) }\end{array}$} & \multirow[t]{4}{*}{ HP } & HIMA & $16.02 \pm 7.75$ & \multirow[t]{4}{*}{$t(8)=-1.73$} & \multirow[t]{4}{*}{$p=0.121$} \\
\hline & & & $\begin{array}{l}(21.71 \pm \\
10.50)\end{array}$ & & \\
\hline & & PIMA & $20.61 \pm 10.16$ & & \\
\hline & & & $\begin{array}{l}(26.61 \pm \\
13.12)\end{array}$ & & \\
\hline & \multirow[t]{4}{*}{ HT } & HIMA & $30.33 \pm 14.60$ & \multirow[t]{4}{*}{$t(8)=-0.12$} & \multirow[t]{4}{*}{$p=0.909$} \\
\hline & & & $\begin{array}{l}(40.65 \pm \\
19.57)\end{array}$ & & \\
\hline & & Twitch & $30.65 \pm 16.76$ & & \\
\hline & & & $\begin{array}{l}(41.42 \pm \\
22.65)\end{array}$ & & \\
\hline & \multirow[t]{4}{*}{ both } & HIMA & $23.17 \pm 13.52$ & \multirow{4}{*}{$\begin{array}{l}z=-0.81, n= \\
18\end{array}$} & \multirow[t]{4}{*}{$p_{\text {exact }}=0.442$} \\
\hline & & & $\begin{array}{l}(31.23 \pm \\
18.22)\end{array}$ & & \\
\hline & & PIMA \& & $25.63 \pm 14.40$ & & \\
\hline & & & $\begin{array}{l}(33.85 \pm \\
19.02)\end{array}$ & & \\
\hline (3.) & \multirow[t]{2}{*}{ HP } & HIMA & $-2.21 \pm 1.51$ & \multirow[t]{2}{*}{$t(8)=0.55$} & \multirow[t]{2}{*}{$p=0.598$} \\
\hline $\mathrm{SvO}_{2}$ slope & & PIMA & $-2.41 \pm 1.59$ & & \\
\hline \multirow[t]{4}{*}{ in $p p s^{-1}$} & \multirow[t]{2}{*}{ HT } & HIMA & $-3.63 \pm 1.56$ & \multirow[t]{2}{*}{$t(8)=-0.94$} & \multirow[t]{2}{*}{$p=0.373$} \\
\hline & & Twitch & $-3.11 \pm 1.31$ & & \\
\hline & \multirow[t]{2}{*}{ both } & HIMA & $-2.79 \pm 1.60$ & \multirow[t]{2}{*}{$t(17)=-0.11$} & \multirow[t]{2}{*}{$p=0.913$} \\
\hline & & PIMA \& & $-2.76 \pm 1.46$ & & \\
\hline
\end{tabular}


Twitch

\begin{tabular}{|c|c|c|c|c|c|}
\hline (4.) & \multirow[t]{2}{*}{$\mathrm{HP}$} & HIMA & $61.96 \pm 3.87$ & \multirow[t]{2}{*}{$t(8)=-0.90$} & \multirow[t]{2}{*}{$p=0.392$} \\
\hline $\mathrm{SvO}_{2}$ at $\mathrm{rHb}$ min. & & PIMA & $62.42 \pm 4.56$ & & \\
\hline \multirow[t]{4}{*}{ in $\%$} & \multirow[t]{2}{*}{$\mathrm{HT}$} & HIMA & $58.66 \pm 2.61$ & \multirow[t]{2}{*}{$t(8)=-0.31$} & \multirow[t]{2}{*}{$p=0.768$} \\
\hline & & Twitch & $58.81 \pm 3.04$ & & \\
\hline & \multirow[t]{2}{*}{ both } & HIMA & $60.31 \pm 3.63$ & \multirow[t]{2}{*}{$t(17)=-0.89$} & \multirow[t]{2}{*}{$p=0.388$} \\
\hline & & $\begin{array}{l}\text { PIMA \& } \\
\text { Twitch }\end{array}$ & $60.62 \pm 4.20$ & & \\
\hline (5.) & \multirow[t]{2}{*}{$\mathrm{HP}$} & HIMA & $7.72 \pm 3.01$ & \multirow[t]{2}{*}{$t(8)=-0.5$} & \multirow[t]{2}{*}{$p=0.630$} \\
\hline TSS & & PIMA & $8.45 \pm 2.72$ & & \\
\hline \multirow[t]{4}{*}{ in $\mathrm{s}$} & \multirow[t]{2}{*}{ HT } & HIMA & $7.61 \pm 2.61$ & \multirow[t]{2}{*}{$t(8)=-1.01$} & \multirow[t]{2}{*}{$p=0.344$} \\
\hline & & Twitch & $8.78 \pm 2.92$ & & \\
\hline & \multirow[t]{2}{*}{ both } & HIMA & $7.67 \pm 2.74$ & \multirow[t]{2}{*}{$t(17)=-1.05$} & \multirow[t]{2}{*}{$p=0.309$} \\
\hline & & $\begin{array}{l}\text { PIMA \& } \\
\text { Twitch }\end{array}$ & $8.62 \pm 2.74$ & & \\
\hline (6.) & \multirow[t]{2}{*}{$\mathrm{HP}$} & HIMA & $44.80 \pm 18.06$ & \multirow[t]{2}{*}{$t(8)=-0.90$} & \multirow[t]{2}{*}{$p=0.394$} \\
\hline TTF & & PIMA & $50.33 \pm 9.46$ & & \\
\hline \multirow[t]{4}{*}{ in $\mathrm{s}$} & \multirow[t]{2}{*}{$\mathrm{HT}$} & HIMA & $42.63 \pm 7.64$ & \multirow[t]{2}{*}{$t(8)=-2.40$} & \multirow[t]{2}{*}{$p=0.043$} \\
\hline & & Twitch & $52.78 \pm 11.61$ & & \\
\hline & \multirow[t]{2}{*}{ both } & HIMA & $43.72 \pm 13.50$ & \multirow[t]{2}{*}{$t(17)=-2.15$} & \multirow[t]{2}{*}{$p=0.047$} \\
\hline & & $\begin{array}{l}\text { PIMA \& } \\
\text { Twitch }\end{array}$ & $51.55 \pm 10.35$ & & \\
\hline
\end{tabular}

Legend: $\mathrm{HIMA}$, holding isometric muscle action; max. $\mathrm{SvO}_{2}$ decrease, maximal deoxygenation; PIMA, pulling isometric muscle action; $\mathrm{SvO}_{2}$ at $\mathrm{rHb}$ min., $\mathrm{SvO}_{2}$ level at global minimum of $\mathrm{rHb} ; \mathrm{SvO}_{2}$ slope, slope of initial linear $\mathrm{SvO}_{2}$ decrease; TTF, time to task failure; TSS, time to leveling off into a steady state of $\mathrm{SvO}_{2}$.

Significant differences are in bold.

Figure 2 illustrates the two occurred behavioral patterns (type I and II) as described in detail by Dech et al. (2020) [13].

Based on curve shapes, Table 2 shows the categorization of all fatiguing tasks and MVIC-tests into type I $(n=9)$ and type II $(n=27)$. The amounts of trials assigned to type I and type II were similar between HIMA 
and PIMA $\left(\chi^{2}(1, n=18)=0.23, p_{\text {exact }}=1.00\right.$ as well as HIMA and Twitch $\left(\chi^{2}(1, n=18)=0.00, p_{\text {exact }}=\right.$ 1.00). This also applies for overall trials (HIMA vs. PIMA (incl. Twitch): $\chi^{2}(1, n=36)=0.15, p_{\text {exact }}=1.00$.

Table 2. Number ( $\mathrm{n}$ ) of type I and type II behaviors of the capillary venous oxygen saturation and blood filling during the tasks separated by groups and overall trials of ten subjects.

\begin{tabular}{|lllllll|}
\hline & \multicolumn{2}{l}{ HP-group } & \multicolumn{2}{l|}{ HT-group } & \multicolumn{2}{l|}{ overall trials } \\
\hline task & HIMA & PIMA & HIMA & Twitch & HIMA & PIMA (incl. Twitch) \\
\hline type I $(\mathrm{n}=9)$ & 4 & 3 & 1 & 1 & 5 & 4 \\
\hline expected & 3.5 & 3.5 & 1 & 1 & 4.5 & 4.5 \\
\hline type II $(\mathrm{n}=27)$ & 5 & 6 & 8 & 8 & 13 & 14 \\
\hline expected & 5.5 & 5.5 & 8 & 8 & 6.8 & 13.5 \\
$\mathrm{n}=36$ & 9 & 9 & 9 & 9 & 18 & 18 \\
\hline
\end{tabular}

Legend: HIMA, holding isometric muscle action; HP-group, PIMA, pulling isometric muscle action.

The correlation coefficients of all 36 trials were $r=0.31(p=0.069)$ between TTF and $\mathrm{SvO}_{2}$ slope; $r=-$ $0.13(p=0.463)$ between TTF and max. $\mathrm{SvO}_{2}$ decrease and $r=-0.88(p<0.001)$ between $\mathrm{SvO}_{2}$ slope and max. $\mathrm{SvO}_{2}$ decrease.

\section{Discussion}

Muscle oxygenation during different muscle actions

In respect of a possible objective distinction of the two isometric forms, oxidative variables were compared between HIMA and PIMA. No significant differences were found regarding the maximal deoxygenation, saturation slopes, saturation level at global minimum of $\mathrm{rHb}$ and time to leveling off into a saturation steady state. This indicates that these variables cannot discriminate HIMA and PIMA on the basis of the small sample size investigated here. Regarding the saturation slopes, this is in accordance with Booghs et al. (2012) [11]. They utilized the near infrared spectroscopy technique (NIRS), which is comparable with our used white light spectrometry $[13,17]$. To our best knowledge, the remaining oxidative variables were considered for the first time regarding the comparison of HIMA and PIMA.

As generally accepted, IMAs should restrict the capillary blood flow due to the high intramuscular pressure already at low intensities $[19,20]$, but the occlusion threshold might vary between individuals and muscles [31]. In contrast, auxotonic contractions possibly support oxygen and blood supply due to the reduced muscle tension during the lowering phase. Comparisons between HIMA and Twitch did not show any significant differences in the analyzed variables of the present study. Thus, the curve characteristics of $\mathrm{SvO}_{2}$ and $\mathrm{rHb}$ seem not to be influenced by twitches. Otherwise, the minimal motion of 
the limb caused by rapid muscle contractions might not be enough to change the muscle oxygenation and blood filling of microvessels significantly.

Previous studies revealed that increases in capillary blood filling $(\mathrm{rHb})[13,15,30,32-34]$ and homeostatic steady states in the oxygen saturation $[11,13-16]$ are possible already during IMAs without twitches. These data suggest a probable maintenance of capillary blood flow. Recently, it was discussed that this could be achieved by the anatomical placement of capillaries within muscle tissue and the oscillatory behavior of muscle fibers during IMA [17].

The behavior of oxygen saturation and blood filling can be differentiated by two types [13], indicated by the $\mathrm{SvO}_{2}$ level at global minimum of $\mathrm{rHb}$ [17]. We have suggested a threshold of $\sim 59 \%$ whereby values above this threshold are associated with type I (parallel behavior of $\mathrm{SvO}_{2}$ and $\mathrm{rHb}$ ) [17]. In contrast, if the saturation decreases below that threshold, $\mathrm{rHb}$ starts to increase which is related to type II. The distribution of type I and type II assigned measurements reflects a qualitative behavior of the measured parameters $\mathrm{SvO}_{2}$ and $\mathrm{rHb}$. Because the extents of deoxygenation and $\mathrm{SvO}_{2}$ levels at global minimum of $\mathrm{rHb}$ did not differ significantly between HIMA and PIMA as well as not between HIMA and Twitch the amount of type I and type II assigned measurements are, as a consequence, not significantly different (Table 2). Thus, the occurrence of type I and type II seems to be independent of the isometric task.

At last, a high and significant negative correlation $(\mathrm{r}=-0.88)$ between the $\mathrm{SvO}_{2}$ decrease and $\mathrm{SvO}_{2}$ slope was found over all measurements. The greater the deoxygenation, the steeper the drop. This is plausible by considering the similar TSSs found over all trials.

\section{Time to task failure during different muscle actions}

The TTF as performance variable in the presented study, appeared to be longer during PIMA compared

to HIMA. However, the difference (5.51 $\pm 18.37 \mathrm{~s})$ was not significantly different (methodological limitations see below). This is in line with the results of other studies which also examined the TTF of the biceps brachii muscle [11] or elbow flexor muscles [3] with similar settings for HIMA and PIMA at the same intensity ( $60 \%$ of the MVIC) and same forearm position (horizontal). However, during lower intensities ( $\leq 30 \%$ of the MVIC) of the elbow flexor muscles, the TTF of HIMA seems to be significantly shorter than the TTF of PIMA $[3,4,9,11]$. If the IMA is, by contrast, performed in a vertical forearm position or during muscle activities at $45 \%$ and $60 \%$ of the MVIC, the TTF was found to be similar between tasks $[3,4]$. This indicates that both, the intensity and forearm position, influences the performance of elbow flexor muscles. Regarding the first dorsal interosseous muscle, Maluf et al. (2005) found differences in the TTF between HIMA and PIMA at $20 \%$ of MVIC (TTF HIMA < TTF PIMA) but not at $60 \%$ [35].

However, the order of tasks in the presented study might have influenced the TTFs in favor of HIMA. In case HIMA was performed at first (in 6 of 9 cases), the relation of PIMA/HIMA amounted to $1.17 \pm 0.68$; in case PIMA was performed at first ( 3 of 9 cases) the relation PIMA/HIMA was $\sim 1.61 \pm 0.53$. 
Additionally, it should be mentioned again that holding tasks as performed in the present and the other mentioned studies does not imply a pure IMA. In general, muscles show slight oscillations during isometric muscle actions $[2,10,36-40]$. Thus, minor muscle shortenings and lengthenings are present. In case of weight holding, slight motions around the given joint angle have been accepted. The tolerance in different studies ranged from $2^{\circ}-10^{\circ}$. This also includes minor concentric contractions to lift the weight back to the starting angle position. Such muscle actions interrupt a pure HIMA and it was hypothesized that the muscle action could be switched to a PIMA after minor concentric contraction has been executed [2]. In the present study, little concentric contractions were documented during four of nine HIMAs in the HP group. This also might have biased the result and might explain why the trend of a longer TTF during PIMA did not reveal statistical significance. Different experimental procedures were applied by Schaefer and Bittmann $(2017,2021)$ examining elbow extensors. The methods might repeal the above-mentioned problem for HIMA during weight holding $[2,10]$. In the first study, a pneumatically driven measurement system was used to realize HIMA and PIMA [2] and in the second one, an interaction between two subjects comparable with arm wrestling [10]. The former study controlled for a concentric contraction (failure criterion) and the latter one facilitates the performance of the tasks described above during PIMA (acting part) and HIMA (reacting part), since the holding subject just had to adapt to the input of the pushing partner. In both studies, the forearm was positioned vertically and significant differences regarding the TTF of elbow extensors at $80 \%$ of the MVIC (TTF HIMA < TTF PIMA) were found. Thus, not only the intensity of muscle activity and positioning but also the examined muscle and experimental procedure might play a role.

In this regard, the present study revealed that intermittent muscle twitches during holding task extended the TTF significantly ( 10 s). It was assumed that the muscle twitches induce a switch of the muscle action from reacting (HIMA) to acting (PIMA) during the isometric phases. Considering PIMA and Twitch together and comparing theses to all HIMA trials, the TTF still differs significantly. As discussed above, the behavior of $\mathrm{SvO}_{2}$ and $\mathrm{rHb}$ in conjunction with variables 1. -5 . were similar between tasks. Thus, the reason for a longer TTF during PIMA (incl. Twitch) seems not to be a different oxygen or blood supply. This is further supported by the analyzed correlations. Independently of the isometric task, very low to low, non-significant correlations between the TTF and the $\mathrm{SvO}_{2}$ decrease as well as the TTF and $\mathrm{SvO}_{2}$ slopes ( $r=-0.13$ and 0.31 , respectively) were found. This result indicate a reasonable independence of the TTF from the deoxygenation as long as $\mathrm{SvO}_{2}$ levels off into a homeostatic steady state. Booghs et al. (2012) also conclude that the decrease in muscle oxygenation is not a significant predictor of the TTF although they did not rule out its contribution to muscle fatigue [11]. Moreover, an enhancement of muscle oxygenation (oxygen half time recovery) as revealed in rock climbers during fatiguing forearm muscle contractions at $60 \%$ of the MVIC by New Zealand blackcurrant extract did not affect the TTF [41]. Consequently, there must be other factors why TTF was found to be extended during Twich. One possibility should be shortly discussed in the following.

It was previously suggested that the neuromuscular control could play a decisive role in the distinction of HIMA and PIMA [2]. This was based on the assumption that PIMA is closer to the motor control processes 
of concentric contraction, and HIMA might show a proximity to eccentric muscle action [2]. Eccentric muscle actions involve more complex control strategies compared to concentric muscle actions possibly resulting in a greater central fatigue $[2,42-46]$. Thus, the more complex control processes suggested for HIMA might be one reason for the often found shorter TTF compared to PIMA [2-4, 9-11]. The significantly longer TTF during Twitch in the present study, could support the assumption of a switch from HIMA to PIMA.

\section{Study limitations}

Limitations regarding the used measurement technique, not examined skinfold thickness and different determinations methods of the MVIC have been described previously $[13,17]$.

Some more limitations need to be emphasized especially regarding the TTF. During HIMA and Twitch, the loading was stopped as soon as the elbow angles exceeded $90^{\circ}$ for more than $2 \mathrm{~s}$ and if twitches were not visible anymore. No objective instrument (e.g., goniometer) was used to reach highest accuracy during control. The measurement error could have influenced individual trials but on group level the random error ought to be leveled out. However, the amplitude and velocity of twitches might have varied between trials. TTFs could also be influenced by the measurement position, as discussed before. Subjects used a horizontal forearm position in all measurements but changed from standing to sitting position between HIMA and PIMA. Thus, activation of trunk stabilizing and postural muscles were different between tasks with an expected higher activity during HIMA (standing). However, the biceps brachii muscle had to be equally activated with $60 \%$ of the MVIC within the muscle chain to maintain a $90^{\circ}$ elbow flexion. If the trunk stabilizing muscles were not strong enough, the whole body would be bend forward. This was prevented by the counter bearing between the upper arm and thorax. Furthermore, due to the exclusion of measurements (see statistical analysis) the sequence of tasks of HP-group were not balanced anymore ( $n=6$ HIMA first; $n=3$ PIMA first). Thus, effects of fatigue might have influenced the results as discussed above. In contrast, the order was nearly balanced in HT group ( $n=5$ HIMA first, $n=4$ PIMA first).

\section{Conclusions}

Muscle oxygenation seem to be similar during HIMA and PIMA (especially the max. deoxygenation and oxygenation level at global minimum of blood filling of the venous capillary system). As a consequence, the behavioral pattern of the parameters $\mathrm{SvO}_{2}$ and $\mathrm{rHb}$ (type I: parallel or type II: partly inverse) occurred independently of the isometric task. In addition, intermittent muscle twitches might not alter their behavior. Possibly, the oxygen and blood supply is already sufficient during IMA without twitches. This could also explain why the TTF did not substantially correlate with the maximal deoxygenation independently of the isometric task.

In respect of the TTF, the study adds data regarding a possible objective distinction between two forms of isometric form. The TTF tend to be shorter during HIMA compared to PIMA of the elbow flexors 
performed in a horizontal forearm position at $60 \%$ of the MVIC. Considering Twitch, the trend reveals statistical significance. More research is necessary in that field, especially at higher intensities $(\geq 60 \%$ $M V I C)$, different muscles and positioning.

Due to the mentioned study limitations, pilot character of the study and scarce literature on that topic, the conclusions should be seen as preliminary.

\section{Abbreviations}

$1^{\text {st }}$ Max. - first local maximum

$1^{\text {st }}$ Min. - first local minimum

$\mathrm{AU}$ - arbitrary units

$\mathrm{BMI}$ - body mass index

BV - blood volume

CV - coefficient of variation

EMG - electromyography

HIMA - holding isometric muscle action

HP - holding vs. pulling group

HAT - holding vs. twitching group

IMA - isometric muscle action

$\mathrm{M}$ - arithmetic mean

max. $\mathrm{SvO}_{2}$ decrease - maximal deoxygenation

MVIC - maximal voluntary isometric contraction

NI DIAdem ${ }^{\mathrm{TM}}$ - National Instruments DIAdem ${ }^{\mathrm{TM}}$

NIRS - near infrared spectroscopy technique

O2C - Oxygen To See; LEA Medizintechnik GmbH

PIMA - pushing or pulling isometric muscle action

$\mathrm{rHb}$ - relative hemoglobin amount 
$\mathrm{RP}$ - reversal point

SD - standard deviation

$\mathrm{SvO}_{2}$ - capillary-venous oxygen saturation of hemoglobin

$\mathrm{SvO}_{2}$ at $\mathrm{rHb}$ min. $-\mathrm{SvO}_{2}$ level at global minimum of $\mathrm{rHb}$

$\mathrm{SvO}_{2}$ slope - Slopes of initial linear $\mathrm{SvO}_{2}$ decrease

$\mathrm{tHb}-$ total hemoglobin

THI - total hemoglobin index

TTF - time to task failure

TSS - time to leveling off into a steady state of $\mathrm{SvO}_{2}$

\section{Declarations}

\section{Ethics approval and informed consent to participate}

The study was conducted according to the declaration of Helsinki and was approved by the ethics committee of the University of Potsdam, Germany (approval No. 28-2017). All subjects gave their written informed consent to participate.

Consent for publication

Not applicable.

\section{Availability of data and materials}

All data generated or analyzed during this study are included in this published article and supplementary material, respectively. Competing interests

The authors declare that they have no competing interests.

\section{Funding}

None.

\section{Authors' contributions}

SD: data analysis, writing original draft of manuscript. FB and LVS: study design. All authors: data collection and interpretation, revision and final approval. 
Acknowledgements

The authors appreciate the technical support of LEA Medizintechnik GmbH. Furthermore, we would like to thank the Deutsche Forschungsgemeinschaft and Open Access Publishing Fund of University of Potsdam.

\section{References}

1. Garner JC, Blackburn T, Weimar W, Campbell B. Comparison of electromyographic activity during eccentrically versus concentrically loaded isometric contractions. J Electromyogr Kinesiol. 2008;18:466-71.

2. Schaefer LV, Bittmann FN. Are there two forms of isometric muscle action? Results of the experimental study support a distinction between a holding and a pushing isometric muscle function. BMC Sports Sci Med Rehabil. 2017;9:11.

3. Rudroff T, Barry BK, Stone AL, Barry CJ, Enoka RM. Accessory muscle activity contributes to the variation in time to task failure for different arm postures and loads. J Appl Physiol. 2007;102:10006.

4. Rudroff T, Justice JN, Holmes MR, Matthews SD, Enoka RM. Muscle activity and time to task failure differ with load compliance and target force for elbow flexor muscles. J Appl Physiol. 2010;110:12536.

5. Rudroff T, Kalliokoski KK, Block DE, Gould JR, Klingensmith WC, Enoka RM. PET/CT imaging of ageand task-associated differences in muscle activity during fatiguing contractions. J Appl Physiol. 2013;114:1211-9.

6. Semmler JG, Kornatz KW, Dinenno DV, Zhou S, Enoka RM. Motor unit synchronisation is enhanced during slow lengthening contractions of a hand muscle. J Physiol. 2002;545:681-95.

7. Dech S, Bittmann FN, Schaefer LV. Assessment of the Adaptive Force of Elbow Extensors in Healthy Subjects Quantified by a Novel Pneumatically Driven Measurement System with Considerations of Its Quality Criteria. Diagnostics. 2021;11:923.

8. Bittmann FN, Dech S, Aehle M, Schaefer LV. Manual Muscle Testing-Force Profiles and Their Reproducibility. Diagnostics. 2020;10:996.

9. Hunter SK, Ryan DL, Ortega JD, Enoka RM. Task Differences With the Same Load Torque Alter the Endurance Time of Submaximal Fatiguing Contractions in Humans. J Neurophysiol. 2002;88:308796.

10. Schaefer LV, Bittmann FN. Paired personal interaction reveals objective differences between pushing and holding isometric muscle action. PLoS One. 2021;16:e0238331.

11. Booghs C, Baudry S, Enoka R, Duchateau J. Influence of neural adjustments and muscle oxygenation on task failure during sustained isometric contractions with elbow flexor muscles. Exp Physiol. 2012;97:918-29. 
12. Kahn JF, Kapitaniak B, Monod H. Comparison of two modalities when exerting isometric contractions. Eur J Appl Physiol. 1985;54:331-5.

13. Dech S, Bittmann F, Schaefer L. Behavior of oxygen saturation and blood filling in the venous capillary system of the biceps brachii muscle during a fatiguing isometric action. Eur $\mathrm{J}$ Transl Myol. 2020;30:79-87.

14. Moalla W, Merzouk A, Costes F, Tabka Z, Ahmaidi S. Muscle oxygenation and EMG activity during isometric exercise in children. J Sports Sci. 2006;24:1195-201.

15. Akima $H$, Ando R. Oxygenation and neuromuscular activation of the quadriceps femoris including the vastus intermedius during a fatiguing contraction. Clin Physiol Funct Imaging. 2017;37:750-8.

16. Katayama K, Yoshitake Y, Watanabe K, Akima H, Ishida K. Muscle deoxygenation during sustained and intermittent isometric exercise in hypoxia. Med Sci Sports Exerc. 2010;42:1269-78.

17. Dech S, Bittmann FN, Schaefer LV. Muscle Oxygenation Level Might Trigger the Regulation of Capillary Venous Blood Filling during Fatiguing Isometric Muscle Actions. Diagnostics. 2021;11:1973.

18. Sadamoto T, Bonde-Petersen F, Suzuki Y. Skeletal muscle tension, flow, pressure, and EMG during sustained isometric contractions in humans. Eur J Appl Physiol Occup Physiol. 1983;51:395-408.

19. Sejersted OM, Hargens AR, Kardel KR, Blom P, Jensen O, Hermansen L. Intramuscular fluid pressure during isometric contraction of human skeletal muscle. J App Physiol. 1984;56:287-95.

20. Sjøgaard G, Savard G, Juel C. Muscle blood flow during isometric activity and its relation to muscle fatigue. Eur J Appl Physiol Occup Physiol. 1988;57:327-35.

21. Jensen BR, Jørgensen K, Hargens AR, Nielsen PK, Nicolaisen T. Physiological Response to Submaximal Isometric Contractions of the Paravertebral Muscles: Spine. 1999;24:2332.

22. Järvholm U, Styf J, Suurkula M, Herberts P. Intramuscular pressure and muscle blood flow in supraspinatus. Eur J Appl Physiol. 1988;58:219-24.

23. Beckert $S$, Witte MB, Königsrainer A, Coerper $S$. The Impact of the Micro-Lightguide $02 C$ for the Quantification of Tissue Ischemia in Diabetic Foot Ulcers. Diabetes Care. 2004;27:2863-7.

24. Jørgensen LP, Schroeder TV. Micro-lightguide spectrophotometry for tissue perfusion in ischemic limbs. J Vasc Surg. 2012;56:746-52.

25. Abel G, Allen J, Drinnan M. A pilot study of a new spectrophotometry device to measure tissue oxygen saturation. Physiol Meas. 2014;35:1769-80.

26. Forst T, Hohberg C, Tarakci E, Forst S, Kann P, Pfützner A. Reliability of Lightguide Spectrophotometry $(\mathrm{O} 2 \mathrm{C} \circledast)$ for the Investigation of Skin Tissue Microvascular Blood Flow and Tissue Oxygen Supply in Diabetic and Nondiabetic Subjects. J Diabetes Sci Technol. 2008;2:1151-6.

27. Joshi D, Shiwalkar A, Cross MR, Sharma SK, Vachhani A, Dutt C. Continuous, non-invasive measurement of the haemodynamic response to submaximal exercise in patients with diabetes mellitus: evidence of impaired cardiac reserve and peripheral vascular response. Heart. 2010;96:3641. 
28. Frank KH, Kessler M, Appelbaum K, Dummler W. The Erlangen micro-lightguide spectrophotometer EMPHO I. Phys Med Biol. 1989;34:1883-900.

29. Knobloch K, Kraemer R, Lichtenberg A, Jagodzinski M, Gosling T, Richter M, et al. Microcirculation of the Ankle after Cryo/Cuff Application in Healthy Volunteers. Int J Sports Med. 2005;27:250-5.

30. Felici F, Quaresima V, Fattorini L, Sbriccoli P, Filligoi GC, Ferrari M. Biceps brachii myoelectric and oxygenation changes during static and sinusoidal isometric exercises. J Electromyogr Kinesiol. 2009;19:e1-11.

31. Bergua P, Montero-Marin J, Gomez-Bruton A, Casajús JA. The finger flexors occlusion threshold in sport-climbers: an exploratory study on its indirect approximation. Eur J Sport Sci. 2021;21:1234-42.

32. Kell RT, Bhambhani Y. Relationship between erector spinae muscle oxygenation via in vivo near infrared spectroscopy and static endurance time in healthy males. Eur J Appl Physiol. 2008;102:243-50.

33. Demura S, Nakada M. Relationships between Force and Muscle Oxygenation Kinetics during Sustained Static Gripping using a Progressive Workload. J Physiol Anthropol. 2009;28:109-14.

34. Usaj A. Differences in the oxygenation of the forearm muscle during isometric contraction in trained and untrained subjects. Cell Mol Biol Lett. 2002;7:375-7.

35. Maluf KS, Shinohara M, Stephenson JL, Enoka RM. Muscle activation and time to task failure differ with load type and contraction intensity for a human hand muscle. Exp Brain Res. 2005;167:165-77.

36. McAuley JH, Marsden CD. Physiological and pathological tremors and rhythmic central motor control. Brain. 2000;123:1545-67.

37. Yoshitake $\mathrm{Y}, \mathrm{Ue} \mathrm{H}$, Miyazaki M, Moritani T. Assessment of lower-back muscle fatigue using electromyography, mechanomyography, and near-infrared spectroscopy. Eur J Appl Physiol. 2001;84:174-9.

38. Schaefer LV, Torick AH, Matuschek H, Holschneider M, Bittmann FN. Synchronization of Muscular Oscillations Between Two Subjects During Isometric Interaction. Eur J TransI Myol. 2014;24:2237.

39. Schaefer LV, Bittmann FN. Coherent behavior of neuromuscular oscillations between isometrically interacting subjects: experimental study utilizing wavelet coherence analysis of mechanomyographic and mechanotendographic signals. Sci Rep. 2018;8:15456.

40. Schaefer LV, Löffler N, Klein J, Bittmann FN. Mechanomyography and acceleration show interlimb asymmetries in Parkinson patients without tremor compared to controls during a unilateral motor task. Sci Rep. 2021;11:2631.

41. Fryer S, Giles D, Bird E, Stone K, Paterson C, Baláš J, et al. New Zealand blackcurrant extract enhances muscle oxygenation during repeated intermittent forearm muscle contractions in advanced and elite rock climbers. Eur J Sport Sci. 2021;21:1290-8.

42. Howatson G, Taylor MB, Rider P, Motawar BR, McNally MP, Solnik S, et al. Ipsilateral motor cortical responses to TMS during lengthening and shortening of the contralateral wrist flexors. Eur $\mathrm{J}$ Neurosci. 2011;33:978-90. 
43. Fang Y, Siemionow V, Sahgal V, Xiong F, Yue GH. Greater Movement-Related Cortical Potential During Human Eccentric Versus Concentric Muscle Contractions. J Neuroysiol. 2001;86:1764-72.

44. Fang Y, Siemionow V, Sahgal V, Xiong F, Yue GH. Distinct brain activation patterns for human maximal voluntary eccentric and concentric muscle actions. Brain Res. 2004;1023:200-12.

45. Enoka RM. Eccentric contractions require unique activation strategies by the nervous system. J App Physiol. 1996;81:2339-46.

46. Perrey S. Brain activation associated with eccentric movement: A narrative review of the literature. Eur J Sport Sci. 2018;18:75-82.

\section{Figures}

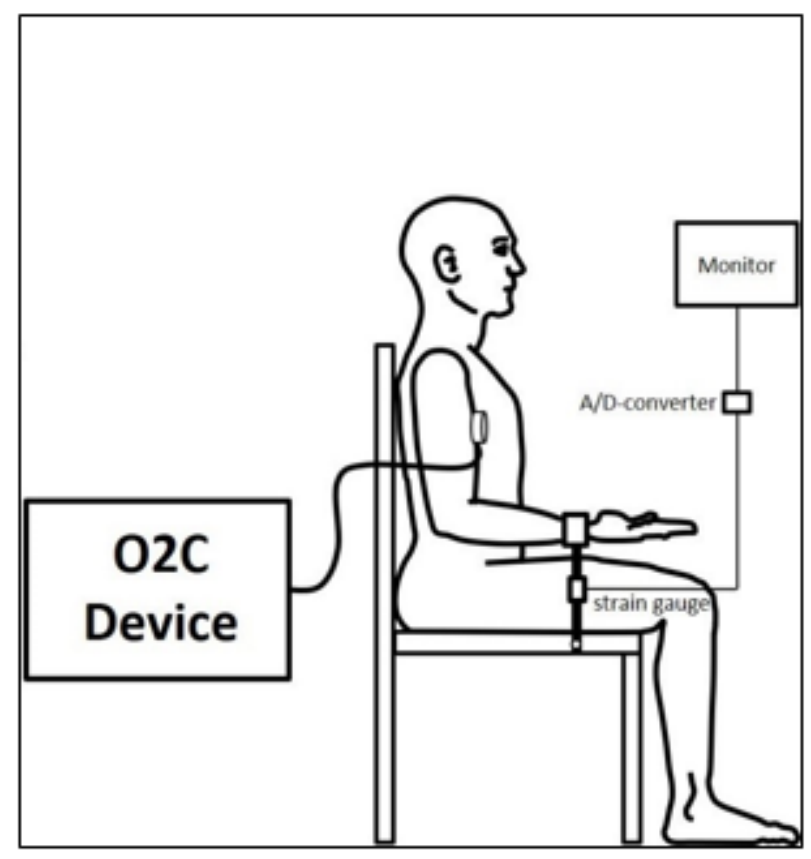

(a)

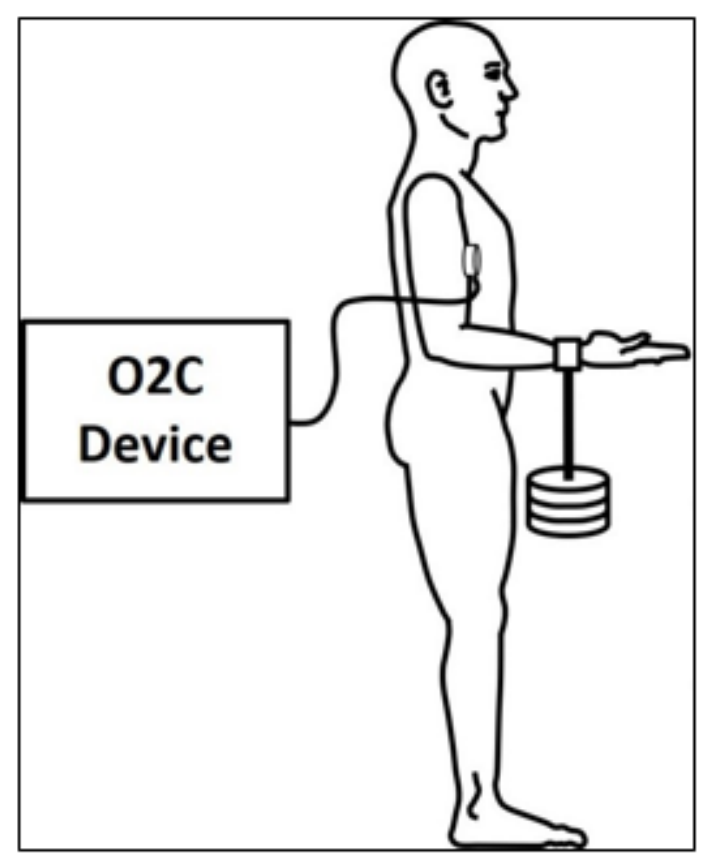

(b)

Figure 1

Positioning and set up during the tasks (a) pulling isometric muscle action (PIMA) as well as (b) holding isometric muscle action (HIMA) and Twitch, reprinted from Dech et al. (2021), with permission [17]. 

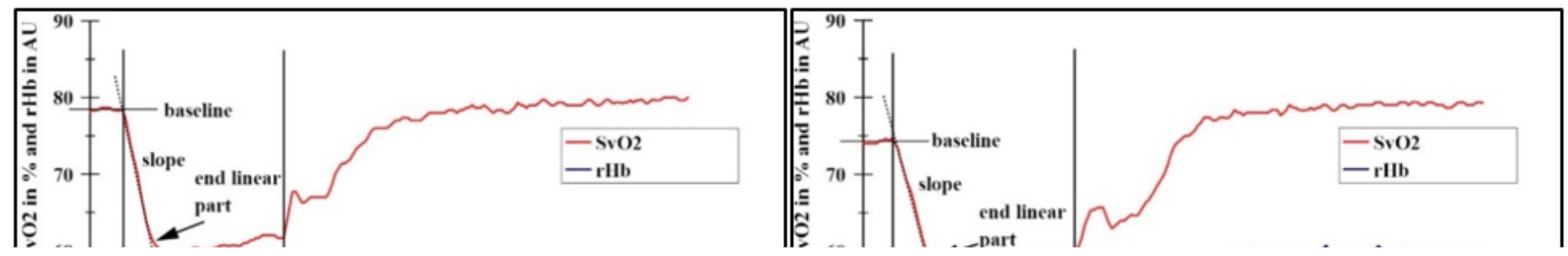

Figure 2

Curve examples of the capillary venous oxygen saturation of hemoglobin $\left(\mathrm{SvO}_{2}\right.$; red) and the relative hemoglobin amount ( $\mathrm{rHb}$, blue) during two fatiguing isometric muscle actions at $60 \%$ of the MVIC of the right biceps brachii muscle of one female (37 yrs, $1.60 \mathrm{~m}, 58 \mathrm{~kg}$ ): (a) HIMA (type I) and (b) PIMA (type II). Start and stop of loading are indicated by vertical lines. Baseline, slope, end of linear slope part and the global minimum are given. The global Min in (b) refers to the reversal point. All curves were smoothed (moving average, maximal smoothing width: 50 ).

\section{Supplementary Files}

This is a list of supplementary files associated with this preprint. Click to download.

- SupplementaryMaterialOxygenTTFTwitchBMC.docx 